\title{
BIOECOLOGIA DE Dermatobia hominis (LINNAEUS Jr., 1781) EM PALOTINA, PARANÁ, BRASIL
}

\author{
BIOECOLOGY OF Dermatobia hominis (LINNAEUS Jr., 1781) \\ IN PALOTINA, PARANÁ, BRAZIL
}

\author{
Simone Benghi Pinto ${ }^{1}$ Vanete Thomaz Soccol $^{2}$ Eliane Vendruscolo $^{1}$ Roberto Rochadelli $^{1}$ \\ Paulo Bretanha Ribeiro ${ }^{3}$ Alaércio Freitag ${ }^{4}$ Carlos Henemann $^{5}$ Márcio Uemura $^{5}$
}

RESUMO

\begin{abstract}
O presente trabalho foi desenvolvido na UFPR Campus Palotina, no Paraná, e em três propriedades rurais do mesmo município, durante o período de novembro de 1997 a maio de 1999. O experimento foi delineado com os objetivos de avaliar: a) a flutuação de larvas de Dermatobia hominis (Linnaeus Jr., 1781) em bovinos da raca Holandesa Preto $e$ Branco criados no município de Palotina, e a distribuição desses ectoparasitos na superfície corporal de bovinos; $e$ b) a sazonalidade dos principais dipteros vetores de ovos de $\boldsymbol{D}$. hominis. Para a captura dos insetos vetores, foram utilizados dois tipos de armadilhas: MAGOON e orientada pelo vento (wind oriented trap $=W O T$ ). Um total de 346 larvas foram expulsas por meio de compressão manual, sendo que a intensidade de larvas foi maior no lado esquerdo do animal, onde foi constatado um total de 240 nódulos (69,36\%). Analisadas as freqüências de nódulos de berne nos animais, ficou demonstrado que houve diferença significativa $(p>0,001)$ na tendência parasitária. Três regiões corpóreas foram mais parasitadas. A primeira é formada pelos membros torácicos, paletas e costelas; a segunda é formada pelo pescoço e flancos, e a terceira, formada pelas regióes dos membros pélvicos, barbela, ventre, cauda e tórax. Durante o período experimental foram capturados, nas armadilhas WOT e de MAGOON, 5.887 dipteros pertencentes a diferentes famílias. Verificou-se que as famílias Calliphoridae, Sarcophagidae e Muscidae foram as mais prevalentes.
\end{abstract}

Palavras-chave: Dermatobia hominis, larvas, bovinos, sazonalidade, vetores.

\section{SUMMARY}

This study was conducted at the Campus Palotina UFPR, in three farms of Palotina county, Paraná State Brazil,

\begin{abstract}
between November (1997) and May (1999) with the intention to evaluate: a) the monthly fluctuation of Dermatobia hominis (Linnaeus Jr., 1781) larvae in Black and White Holstein bovines and the larvae distribution on the body surface and $b$ ) the seasonal distribution of diptera of D. hominis eggs vector. For insects collection two traps types were used: MAGOON and Wind Oriented Trap (WOT). A total of $346 \mathrm{D}$. hominis larvae were expelled by manual compression. By analyzing the nodules frequencies of $\boldsymbol{D}$. hominis larvae in animals a significant difference $(p>0.001)$ relative to localization of parasites was observed. The infestation intensity was bigger in the left side of animals where a total of 240 nodules was observed, representing a relative frequency of $69.36 \%$. According to the number of parasites it higher intensity, in three regions of animal's body was found. The first region was composed by foreleg, chuck and ribs. The second one formed by neck and flanks and the last one by the pelvic members, abdomen, tail and thorax. During the experimental period, 5887 Diptera specimens were caught by MAGOON and WOT traps, classified in different Diptera families; the most abundant families were: Calliphoridae, Sarcophagidae and Muscidae.
\end{abstract}

Key words: Dermatobia hominis, larvae, bovines, vectors, seasonal.

\section{INTRODUÇÃO}

O parasitismo dos insetos representa uma adaptação com o fim de satisfazer as necessidades alimentares e de habitat em diferentes estádios do ciclo de vida. Para alguns insetos, o parasitismo

\footnotetext{
${ }^{1}$ Docentes da Universidade Federal do Paraná (UFPR), Campus Palotina.

${ }^{2}$ Docente da UFPR, Centro Politécnico, Setor de Ciências Biológicas, Departamento de Patologia Básica, 81531-990, Curitiba, PR, Brasil. E-mail: vasoccol @ bio.ufpr.br. Autor para correspondência.

${ }^{3}$ Docente da Universidade Federal de Pelotas.

${ }^{4}$ Discentes da UFPR, Campus Palotina.

${ }^{5}$ Discente da Universidade Estadual do Oeste do Paraná.
} 
fornece uma fonte alimentar e habitat para os adultos. Para outros, o parasitismo pode representar uma fonte alimentar para as larvas (BARNES, 1984; GOMES et al., 1998).

Dentre os ectoparasitos de importância médico-veterinária para a América Latina, está a Dermatobia hominis (LINNAEUS JR., 1781) (Díptera, Oestridae, Cuterebrinae), conhecida popularmente por "mosca do berne". A larva do referido inseto é responsável por miíases furunculosas de bovinos e demais animais domésticos e selvagens, inclusive o homem. $\mathrm{O}$ ciclo biológico da D. hominis é bastante complexo, passando por uma fase de vida livre (pupa no solo e adultos vivendo em ambientes florestais). As fêmeas, após a fecundação, capturam insetos para transportarem seus ovos. A fase subseqüente corresponde à parasitária (larvas do $1^{\underline{0}}$. ao $3^{\circ}$. estádio). O parasitismo pela larva de $\boldsymbol{D}$. hominis é denominado dermatobiose e está presente na América tropical e subtropical. Nos diferentes países da América Latina, as larvas de $\boldsymbol{D}$. hominis apresentam nomes populares que variam conforme o país. No Brasil e Uruguai, são conhecidas por "berne", "ura" ou "kturn" (entre índios Kaingang); na Bolívia, por "gusano peludo"; no Peru, por "mirunta"; na Colômbia, por "nuche"; na Argentina e no Paraguai por "ura"; no México e na Guatemala, por "colmoyote"; na Venezuela, por "gusano macaco"; no Equador, por "tupe"; no Suriname, por "muskietenworm" (GUIMARÃES \& PAPAVERO, 1999).

Entre os fatores que mais influem no desenvolvimento da fase de vida livre da $\boldsymbol{D}$. hominis, estão a temperatura e a precipitação pluviométrica. Por ser um inseto pecilotérmico, sua população flutua, ao longo do ano, nas regiões subtropicais, conforme a disponibilidade térmica (CARRERA, 1991; BATISTA, 1998). A larva, após completar seu ciclo no hospedeiro, cai ao solo para aí penetrar e pupar. O sucesso biológico da fase de vida livre dependerá da textura do solo (seco ou úmido) e da temperatura que a larva encontrar. $\mathrm{O}$ percentual de emergência de pupas que caem em solo seco varia de 1 a $3 \%$, enquanto que em solo úmido este percentual pode atingir 40 a $50 \%$ (ANDERSEN, 1962).

A incidência de larvas de $\boldsymbol{D}$. hominis, em determinadas áreas da superfície tegumentar dos bovinos, tem sido abordada por vários autores. SANCHO et al. (1981) observaram que o costado esquerdo foi significativamente mais infestado que o direito e que os animais de pelagem branca apresentavam menor grau de infestação em relação às outras cores de pelagem. MAIA \& GUIMARÃES
(1985), ao examinarem a distribuição sazonal de larva de $\boldsymbol{D}$. hominis em bovinos da raça Nelore, no município de Governador Valadares, MG, verificaram que, em um mesmo rebanho, alguns animais são mais parasitados pelo "berne", sendo a região das paletas a mais acometida. BELLATO et al. (1986) constataram uma predisposição significativa de infestação em animais de pelagem escura, tanto em grandes como em baixas infestações, sendo as costelas, escápulas, membros anteriores e pescoço as regiões de maior freqüência de larvas. MAGALHÃES \& LIMA (1988), examinando a freqüência de larvas de $\boldsymbol{D}$. hominis em bovinos do município de Pedro Leopoldo, MG, observaram que o costado é a região corporal dos bovinos mais susceptível.

O conhecimento da fauna entomológica rural se faz necessário em qualquer tipo de exploração zootécnica, com o propósito de fazer o controle de certas espécies de insetos que transmitem agentes patogênicos aos animais domésticos e, por consequiência, influem na produção agropastoril. Inúmeras espécies de dípteros foram catalogadas como vetores dos ovos da $\boldsymbol{D}$. hominis, pertencentes às famílias Culicidae, Simuliidae, Anthomyiidae, Muscidae, Tabanidae, Fanniidae, Sarcophagidae e Calliphoridae (GUIMARÃES \& PAPAVERO, 1999). PALOSCHI et al. (1984) mencionam a Musca domestica (Linnaeus 1758) e a Fannia sp. como vetores da $\boldsymbol{D}$. hominis no planalto catarinense. RIBEIRO et al. (1985), estudando os vetores de D. hominis, no Rio Grande do Sul, registraram como vetores a Fannia sp., Stomoxys calcitrans (Linnaeus, 1758), M. domestica, Phaenicia sp. e Tabanus sp. GOMES et al. (1998), na região de cerrados de Campo Grande, MS, constataram as seguintes espécies de dípteros veiculadores de ovos de D. hominis: Fannia spp., Chrysomya albiceps (Wiedemann, 1819), Chrysomya putoria (Wiedemann, 1818) e Sarcopromusca pruna (Shannon \& Del Ponte, 1926). BATISTA (1998), estudando o ciclo silvestre e a ecologia das infestações de bovinos pelas larvas de $\boldsymbol{D}$. hominis, no município de Pedro Leopoldo, MG, verificou que Fannia heydenii (Wiedemann, 1830) é a espécie com maior importância epidemiológica para a manutenção da dermatobiose na região metalúrgica de Minas Gerais.

As perdas ocasionadas pelas larvas de $\boldsymbol{D}$. hominis em bovinos são traduzidas pela diminuição da produção de leite e de carne e pelo baixo ganho de peso. O couro é o subproduto que maior depreciação sofre, o que leva a sua desvalorização comercial ou inadequação à industrialização. As larvas localizam-se normalmente na região do couro 
com maior valor industrial, podendo inutilizar até 70\% (OLIVEIRA, 1991; GOMES et al., 1988).

No estado do Paraná, os dados sobre a infestação por larvas de $\boldsymbol{D}$. hominis em bovinos da raça Holandesa Preto e Branco e sobre os dípteros vetores de seus ovos são escassos. Com o escopo de contribuir para o conhecimento da bioecologia da $\boldsymbol{D}$. hominis no estado do Paraná, foi realizado um experimento com os seguintes objetivos: a) avaliar a freqüência mensal de larvas de $\boldsymbol{D}$. hominis em bovinos da raça Holandesa Preto e Branco e a distribuição desses ectoparasitos na superfície corporal dos animais, ao longo do ano; e b) estimar a sazonalidade das principais famílias vetoras de $\boldsymbol{D}$. hominis no município de Palotina, Paraná.

\section{MATERIAL E MÉTODOS}

A parte experimental do presente trabalho foi desenvolvida no município de Palotina, no período compreendido entre novembro de 1997 a maio de 1999. Palotina localiza-se na região Noroeste do estado do Paraná, região esta conhecida como vale do Rio Piquiri. Os valores da temperatura média no referido município sofrem pequenas variações anuais e oscilam entre $18^{\circ} \mathrm{C}$ e $24^{\circ} \mathrm{C}$ (IAPAR, 1976).

O trabalho foi desenvolvido em três propriedades rurais que são basicamente minifúndios com diversificação de culturas, dentre elas a bovinocultura leiteira, a suinocultura e a atividade agrícola. Nas mesmas propriedades, existem áreas de bosques e pomares, habitat ideal da $\boldsymbol{D}$. hominis e dos dípteros vetores de seus ovos. A agrobiocenose estabular é representada pelas áreas das instalações e construções físicas da fazenda, destacando-se os estábulos, a área de repouso e currais e estábulos, onde os animais são alimentados, cavalariça e as instalações de manejo do gado. A agrobiocenose pastoril é constituída de Cynodon sp. e Tyfton sp.

Para estimativa da flutuação populacional e distribuição corporal de larvas de $\boldsymbol{D}$. hominis em bovinos da raça Holandesa Preto e Branco, foram utilizados 12 animais fêmeas, de aproximadamente três anos, criados em regime semi-intensivo, devidamente identificados com brincos. Os animais, pertenciam a três propriedades rurais distintas, que distanciavam $10 \mathrm{~km}$ entre si (foram acompanhados quatro animais por propriedade). Durante a fase experimental, os animais não receberam tratamento contra ectoparasitos.

Mensalmente, em intervalos de aproximadamente 28 dias, durante um período de 17 meses, os animais foram levados ao curral, onde, pela inspeção visual e tátil, a população de "berne" era contada e mapeada conforme sua distribuição no corpo do hospedeiro. A contagem dos furúnculos larvais na superfície corpórea dos bovinos foi realizada em cada lado do animal, visando a uma comparação do parasitismo.

O corpo do bovino foi dividido em 16 regiões (RIBEIRO et al., 1989), a saber: orelhas, cabeça, pescoço, barbela, tórax, membros torácicos, paletas, costelas, flancos, anca, períneo, cauda, membros pélvicos, virilha, úbere e ventre. Durante as contagens, as larvas foram expulsas através da compressão manual dos nódulos presentes no tecido subcutâneo. Para a flutuação populacional foi considerada a média do total de larvas encontradas mensalmente em bovinos ao longo do ano.

A coleta e identificação dos dípteros capturados nas armadilhas foram realizadas em duas etapas. A primeira correspondeu à etapa de campo, onde foram feitas as coletas de possíveis insetos vetores. A segunda etapa correspondeu à identificação dos insetos coletados. A primeira etapa foi executada em duas propriedades rurais do município de Palotina (mesmo local onde foi realizado o estudo da distribuição corporal das larvas de D. hominis). Consistiu de capturas de insetos aprisionados em dois tipos de armadilhas: MAGOON (1935) modificada por ROBERTS (1965) e orientada pelo vento (WOT = Wind Oriented Trap), descrita por BROCE et al. (1977) e modificada por OLIVEIRA (1982). Essas armadilhas foram colocadas em duas áreas ecológicas distintas: eubiocenose (representada por uma mata que se assemelha a capões, constituída por árvores com aproximadamente $10 \mathrm{~m}$ de altura, entremeadas com alguns representantes de leguminosas e de eucaliptos, dentre algumas outras essências florestais) e agrobiocenose pastoril (representada por pastos).

Nas duas propriedades, as armadilhas de MAGOON foram ativadas duas vezes por mês, colocando-se no seu interior um bezerro com aproximadamente três meses de idade. $\mathrm{O}$ animal permanecia na armadilha durante 24 horas e coletavam-se todos os insetos que aí ficavam. Uma vez recolhidos, os insetos eram levados ao laboratório, onde se procedia à contagem e identificação.

As duas armadilhas WOT permaneceram instaladas 24 horas por dia, durante todo o período experimental. A armadilha constou basicamente de um balde com capacidade de 10 litros, em que se retirou o fundo e colocou-se uma peneira removível por onde foram feitas a exposição da isca e a coleta dos dípteros.

$\mathrm{Na}$ borda do recipiente adaptou-se um funil telado com uma pequena abertura para a entrada dos muscóides, em que também foi fixada uma aleta de metal (alumínio) que direcionou a 
abertura da armadilha no sentido do vento. $\mathrm{Na}$ porção inferior da armadilha, foi fixado um pêndulo, o que evitou o movimento lateral da mesma $\mathrm{e}$ manteve o movimento giratório.

A estimativa da flutuação populacional foi feita por meio da média mensal por armadilha e por família dos espécimes capturados de novembro de 1997 a abril de 1999. Os dados meteorológicos de temperatura e precipitação pluvial foram obtidos junto ao Campo Experimental e Demonstrativo da COOPERVALE e junto ao IAPAR.

\section{RESULTADOS E DISCUSSÃO}

As oscilações climáticas verificadas no decorrer do trabalho encontram-se dentro dos limites favoráveis ao desenvolvimento das fases de vida livre de D. hominis. Quanto à sazonalidade de larvas de D. hominis em bovinos, houve infestações ao longo de todo o período experimental, tendo sido contados 346 nódulos de 'berne'. Os picos populacionais de larvas de $\boldsymbol{D}$. hominis em bovinos ocorreram quando a temperatura média, em ascensão, atingia $24^{\circ} \mathrm{C}$, e a população decresceu com temperatura inferior a $18^{\circ} \mathrm{C}$. $\mathrm{O}$ pico máximo de infestação por larvas foi observado no mês de dezembro (Figura 1). Nesse mês, foi constatado um total de 115 nódulos, o que representa uma freqüência relativa de $33,00 \%$ do total de larvas coletadas no período analisado. Comportamento semelhante foi observado por MAGALHÃES \& LESSKIU (1982), em Ponta Grossa, Paraná, Brasil (verão com temperatura superior a $22^{\circ} \mathrm{C}$ e inverno temperatura inferior a $15^{\circ} \mathrm{C}$ ).

Além da temperatura, observa-se que a precipitação também influenciou a população de larvas no hospedeiro. Como as larvas (L3) que encontram solo úmido têm maior chance de puparem e eclodir, e o período pupal varia de 33 a 49 dias (NEEL, 1954), os meses subseqüientes às chuvas (dezembro/97, janeiro a setembro/1998) mostraram uma população maior de larvas nos hospedeiros. Nos meses secos (maio a julho/1998), houve um decréscimo no número de nódulos. Esses dados assemelham-se aos de KONNE \& BANEGAS (1959) e OLIVEIRA (1991), que relatam para a América Latina a dermatobiose com maior intensidade na época chuvosa e menor população na época seca. A flutuação populacional de larvas de $\boldsymbol{D}$. hominis em Palotina, Paraná, foi similar a encontrada por RIBEIRO et al. (1989) em Pelotas, $\mathrm{RS}$, diferindo apenas na intensidade e na presença significativa de larvas em setembro e outubro. Essa diferença deve-se, provavelmente, às diferenças climáticas existentes entre essas regiões (a temperatura, em Pelotas, varia de $13^{\circ} \mathrm{C}$ a $22^{\circ} \mathrm{C}$ e, em Palotina, $18^{\circ} \mathrm{C}$ a $25^{\circ} \mathrm{C}$; a localização de Pelotas: $31^{\circ} 20^{\prime}$ a $31^{\circ} 48^{\prime}$ latitude sul, $52^{\circ} 45^{\prime}$ longitude oeste e $13,24 \mathrm{~m}$; e Palotina: $24^{\circ} 18^{\prime}$ latitude sul, $53^{\circ} 55^{\prime}$ 'longitude oeste e $310 \mathrm{~m}$ ).

Analisadas as frequiências de nódulos de berne em cada lado (direito/esquerdo) do animal, ficou demonstrado que houve diferença significativa ( $>>0,001)$ na infestação parasitária. A intensidade foi maior no lado esquerdo do animal, no qual foi constatado um total de 240 nódulos, o que representa uma frequiência relativa de $69,36 \%$. Esse resultado pode ser justificado pelo fato de os bovinos repousarem, geralmente, em decúbito látero-esternal direito para facilitar a ruminação. Nossos dados corroboram com os resultados encontrados por OLIVEIRA (1991), que estudou a dinâmica parasitária de bernes em bovinos.

Em relação à intensidade parasitária, verificou-se que as larvas agrupam-se preferencialmente em três regiões corpóreas. A primeira é formada pelos membros torácicos, paletas e costelas, com as frequiências relativas de intensidade de 41,91\%, $21,10 \%$ e $17,05 \%$, respectivamente, totalizando em $80,06 \%$ das infestações. A segunda região é formada pelo pescoço e flancos, com freqüências de 6,36\% e $5,49 \%$, respectivamente. A última é formada pelas regiões dos membros pélvicos, barbela, ventre, cauda e tórax, que apresentaram freqüências de infestações computadas como as menores, de $2,89 \%$, $2,60 \%, 1,44 \%, 0,87 \%$ e $0,28 \%$, respectivamente, alcançando a soma de $8,08 \%$ do total. As infestações de larvas nos membros torácicos, nas paletas e nas costelas merecem destaque, uma vez que são as regiões corpóreas que compõem a parte industrializável da pele do animal e representam, dessa forma, a maior causa de prejuízo econômico.

Durante o período experimental, foram capturados 5.887 insetos nas armadilhas WOT e MAGOON. Do total de insetos capturados, 5.863 pertenciam a oito famílias de dípteros, sendo que as famílias Calliphoridae, Sarcophagidae e Muscidae foram capturadas em todos os meses do período experimental. Entretanto, o número de espécimens mensal da família Calliphoridae capturados foi superior ao das demais famílias (Tabela 1). Outras famílias de dípteros que participaram com diferentes números de exemplares foram: Fanniidae $(1,2 \%)$, Culicidae (1,2\%), Drosofilidae $(0,4 \%)$, Tabanidae $(0,2 \%)$ e Syrphidae $(0,1 \%)$. Segundo vários autores, que realizaram trabalhos em diferentes regiões do Brasil, essas famílias foram notificadas como veiculadoras de ovos de $\boldsymbol{D}$. hominis (GUIMARÃES 


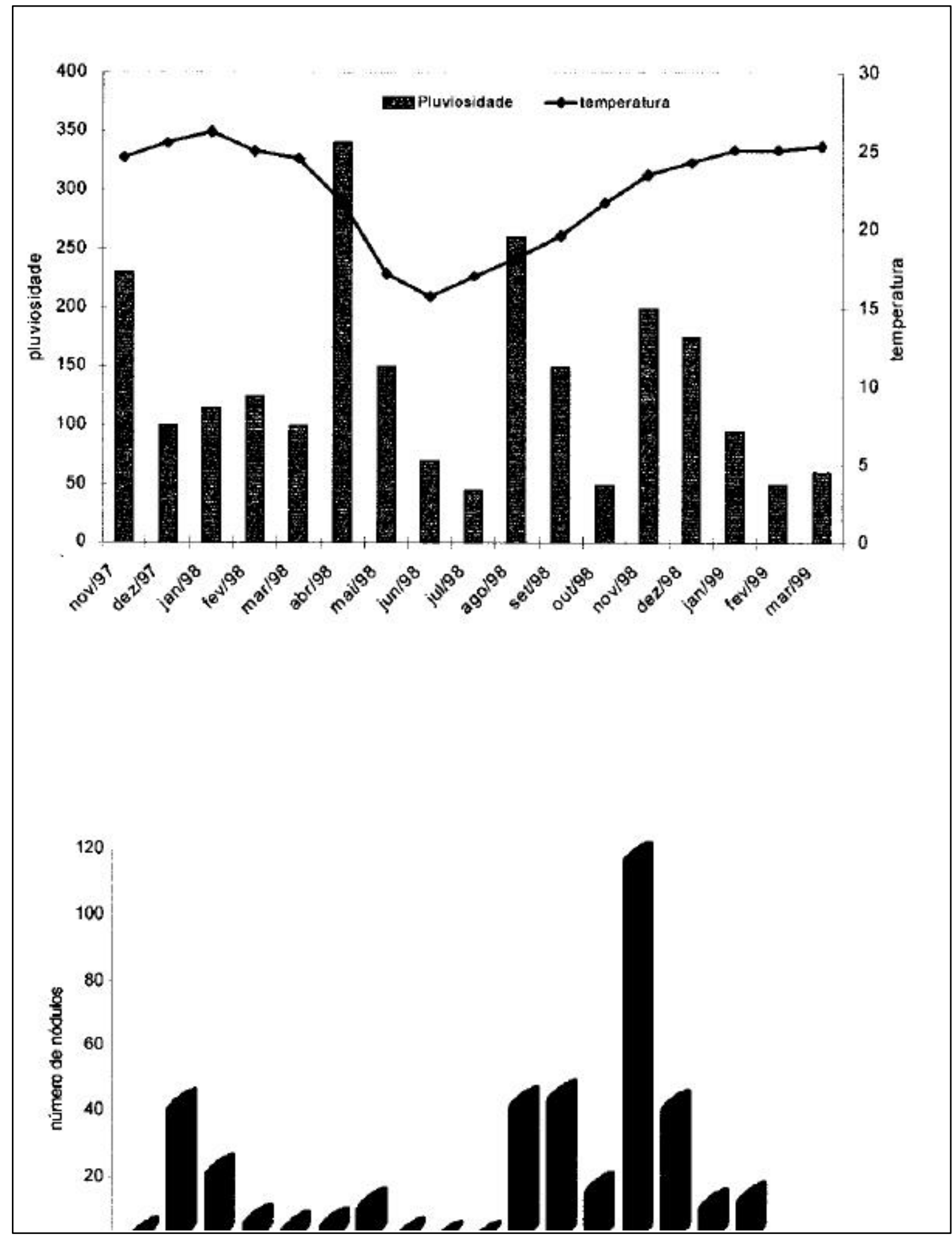

Figura 1 - Número de nódulos formados por larvas de Dermatobia hominis em bovinos holandês preto e branco na região oeste do Paraná, no período de novembro de 1997 a março de 1999 e correlação com dados climáticos. 
et al., 1983; PALOSCHI et al., 1984; KASAI et al., 1990; BATISTA 1998). No entanto, no presente trabalho, apenas um exemplar de Fannia tumidifemur Stein, 1911 foi capturado na armadilha de MAGOON, no mês de março de 1999, portando ovos de $\boldsymbol{D}$. hominis.

As maiores capturas de dípteros foram verificadas nos meses de setembro a março, período de primavera e verão, e as menores nos meses de abril a junho, período que corresponde ao outono. Esses resultados são semelhantes aos encontrados por GOMES et al. (1998) quando estudaram os vetores de ovos de $\boldsymbol{D}$. hominis nos cerrados do Mato Grosso do Sul.

Apesar de as maiores capturas terem ocorrido na primavera e no verão, estas não foram significativamente $(p>0,01)$ diferentes pela análise de variância, daquelas verificadas nos períodos de outono e inverno.

\section{CONCLUSÕES}

Larvas de Dermatobia hominis esteve presente em bovinos da raça Holandesa Preto e Branco no município de Palotina, Noroeste do estado do Paraná, durante todo ano,

No período de verão e outono ocorre os maiores índices de infestação por este ectoparasito,

As larvas localizaram-se preferencialmente nas regiões de membros dianteiros, paletas e costelas,

Oito famílias de dípteros foram registradas nesta região: Calliphoridae, Sarcophagidae, Muscidae, Fanniidae, Culicidae, Drosofilidae, Tabanidae e Syrphidae.

Um exemplar de Fannia tumidifemur foi encontrado portando ovos de Dermatobia hominis.

\section{REFERÊNCIAS BIBLIOGRÁFICAS}

ANDERSEN, E.H. Control of Dermatobia hominis in Central America. Vet Rec., v.74, p.784-787, 1962.

BARNES, R. D. Zoologia dos vertebrados. 4. ed. São Paulo: Roca, 1984. 1179p.

BATISTA Z.R. Dermatobia Hominis (L. Jr., 1781) (Díptera: Oestridae: Cuterebrinae): ciclo silvestre e ecologia das infestaç̃es de bovinos pelo berne no município de Pedro Leopoldo, MG, Brasil. Belo Horizonte, 1998. 101p Tese (Doutorado em Parasitologia) - Curso de Pós-graduação em Parasitologia, Universidade Federal de Minas Gerais, 1998.
BEllato, V., PAlOSCHI, C.G., SOUZA, A.P. de, et al. Variação sazonal das larvas da mosca do berne em bovinos no planalto catarinense. Com Téc EMPASC, Florianópolis v.101, p.1-7, 1986

BROCE, A.B., GOODENOWGH, J.L., COPPEDGE, J.R. A wind oriented trap for screwworm flies. J Econ Entomol, v.70, n.4, p.413-6, 1977

CARRERA, M. Insetos de interesse médico e veterinário. Curitiba : UFPR, 1991. 228p.

GOMES,A., SOUSA, J., RESENDE, A.M., et al. Distribuição corporal e sazonalidade do berne (larva de Dermatobia hominis) em bovinos tratados ou não com flor de enxofre. Pesq Agropec Bras, v.23, n.8, p.825-829, 1988.

GOMES, A., KOLLER, W.W., HONER, M.R., et al. Vetores de ovos de Dermatobia hominis (Diptera: Cuterebridae) na região de cerrados do Mato Grosso do Sul, Brasil. Rev Bras Parasit Vet, v.7, n.1, p.37-40, 1998.

GUIMARÃES, J.H., PAPAVERO, N., PRADO, A.P. As miíases na região neotropical (identificação, biologia e bibliografia). Rev Bras Zool, v.1, n.4, p.379-414, 1983.

GUIMARÃES, J.H., PAPAVERO, N. Myiasis in man and animals in the Neotropical region. São Paulo: Plêiade/FAPESP, 1999. 308p.

IAPAR Manual agropecuário para o Paraná. Londrina: Fundação Instituto Agronômico do Paraná, 1976. v.1.

KASAI, N., SCHUMAKER, T.T.S., DELL'PORTO, A., et al. Variação sazonal de dípteros capturados em armadilhas de MAGOON modificada, em Santana do Parnaíba, Estado de São Paulo. Rev Bras Entomol, v.34, n.2, p.369-380, 1990.

KONN H.D., BANEGAS, A.D. Biology and control of Dermatobia hominis in Honduras (Diptera: Cuterebridae) J Kans Entomol Soc, v.32, p.100-108, 1959.

MAGALHÃES, F.E.P., LESSKIU, C. Efeito do controle do berne sobre o ganho de peso e qualidade dos couros em novilhos de corte. Pesq Agropec Bras, v.17, n.2, p.329- 36, 1982.

MAGALHÃES, F.E.P., LIMA, J.D. Freqüência de larvas de Dermatobia hominis (Linnaeus Jr., 1781), em bovinos em Pedro Leopoldo, Minas Gerais. Arq Bras Med Vet Zoot, Minas Gerais, v.40, n.5, p.361-367, 1988. 
MAGOON, E.H. A portable stable trap for capturing mosquitoes. Bull Entomol Res, v.26, p.363-369, 1935.

MAIA, A.A.M., GUIMARÃES, M.P. Berne: Susceptibilidade de Bovinos, Distribuição no Hospedeiro, Associação com outras Miíases e Abscessos. Arq Bras Med Vet Zoot, Minas Gerais, v.37, n.5, p.461-7, 1985.

NEEL W.W. Control of human bot fly on cattle. J Econ Entomol,v.47,p.540-541, 1954.

OLIVEIRA, C.M.B. Ocorrência e flutuação populacional de três espécies do gênero Chrysomyia. Pesq Agropec Bras, v.17, p.1707-1708, 1982.

OLIVEIRA, G.P. Dinâmica parasitária de bernes em bovinos. I. Incidência em relação ao decúbito. Pesq Agropec Bras, Série Zootecnia, v.26, n.4, p.7-471, 1991.

PALOSCHI, C.G., RAMOS, C.I., SOUZA, A.P. de, et al. Vetores de ovos de Dermatobia hominis (Diptera: Cuterebridae) no planalto catarinense. In: CONGRESSO
BRASILEIRO DE MEDICINA VETERINÁRIA, 19, 1984 Belém, PA. Anais... Belém : Sociedade Paraense de Medicina Veterinária, 1984. p.19.

RIBEIRO, P.B., OLIVEIRA, C.M.B., COSTA, P.R.P., et al. Foréticos da Dermatobia hominis (L. Jr., 1781) (Diptera: Cuterebridae), no Rio Grande do Sul, Brasil. Arq Bras Med Vet Zoot, v.37, n.5, p.507-509, 1985.

RIBEIRO, P.B., COSTA, P.R.P., BRUM, J.G.W., et al. Flutuação populacional de Dermatobia hominis (L. Jr., 1781) sobre bovinos no município de Pelotas, RS. Arq Bras Med Vet Zoot, v.41, n.3, p.223-231, 1989.

ROBERTS, R.H. A Steer-baited trap for sampling insects affecting cattle. Mosquito News, v.25, n.3, p.281-285, 1965.

SANCHO, E., BOLAÑOS, J., TORRES, L. Estudio del tórsalo en el ganado vacuno: análisis preliminar de la distribución en el animal y posibles factores que intervienen en la parasitosis. Ciência Veterinária, v.3, n.2-3, p.157-162, 1981. 